\title{
Impact of Educational Program about Self-care Practices on the Reliving of Vaginal Infection among High Risk Women in Ismailia City
}

\author{
Zeinab A. Baraia ${ }^{1}$; Inas M. Abdallah ${ }^{2}$; Sanaa A. Nour ${ }^{3}$ \\ ${ }^{I}$ Assist. Lecturer, Maternity, Obstetrical and Gynecological Nursing, Faculty of Nursing, Suez Canal University \\ ${ }^{2}$ Assist. Prof., Maternity, Obstetrical and Gynecological Nursing, Faculty of Nursing, Suez Canal University \\ ${ }^{3}$ Prof. Maternity, Newborn Health Nursing, Faculty of Nursing, Zagazeg University
}

\begin{abstract}
The women vulnerability to vaginal infection might be affected by their utilization of vaginal hygienic practices. Aim, is to evaluate the impact of self-care practices program for women diagnosed with vaginitis on their response to the protocol of management in Ismailia City. Design, quasi-experimental study was adopted. Settings, available primary health care centers in Ismailia city were included in this study. Total of 124 women (60 study, 64 control) diagnosed with vaginal infection were enrolled. Tools of data collection included; structure interviewing questionnaire to evaluate self-care practices about genital hygiene as well as follow-up sheet to evaluate women response to protocol of management. Results, Women were more likely to use incorrect technique of self-care practices before the program. However, statistically significant improvement in utilizing adequate practice was revealed in all areas of self-care practices for study group at both the post and follow-up phases ( $p<0.001)$. Conclusion: the women receiving self-care practices program show an improvement of their self-care practices and response to vaginal infection and had less recurrence than those who did not receive the program. Recommendation: A brochure about hygienic self-care practices should be disseminated to vulnerable women and their husbands. Involve healthcare provider to consider the instruction about proper feminine, menstrual and personal hygiene for women.
\end{abstract}

Keywords: Vaginal infection, self-care practices

\section{Introduction}

One of the common gynecologic problems in the general women population is vaginitis. The prevalence of vaginal infections is often varied between countries, were ranged between 20 to $40 \%$ of population [1, 2]. Studies involving different levels of society report the prevalence of abnormal vaginal discharge as $12.1 \%$ to $30 \%[3,4]$. Infection of the female genital tract can result in vaginitis, cervicitis, and urethritis has been associated with adverse pregnancy outcomes [5].

National health service choices (NHS)[6] expressed that, wearing tight-fitting dress, nylon or Lycra underwear expand the danger of infection, which trap warmth and dampness. Yeast infections are frequently seen after the woman takes antibiotics agents for another infection. The antibiotics interfere with the ordinary parity of life forms from the vagina. Furthermore, the utilization of oral contraceptives additionally expands a glycogen store in the vagina which encourages yeast development [7].

Sexual mal- practices as the increase the frequency of sexual intercourse, the initiation of sexual activity (newly married), multiple sex partners or oro-genital sex consider the main risk of behaviors. Vaginal unhygienic practices comprised many practices as douching or using strong soap for washing. Cleansers with alkaline $\mathrm{pH}$ exasperate the sensitive natural equalization and along these lines the $\mathrm{pH}$ of the vagina and the perineum expand the danger for infection and irritation. Unnecessary cleaning is a standout amongst the most widely recognized reasons for aggravation contact dermatitis. Talcum powder, antiperspirants, and antiseptic utilized for better perineal cleanliness may block sweat organs and may bring about sensitization and irritant action and strip the vulva and perineum off its dampness creating dryness and then increase the risk for infections [8].

Infertility, ectopic pregnancy, pelvic inflammatory disease (PID), cervical cancer, every one of them is entanglements of vaginal infection. Besides, build a woman danger of gaining human immune-deficiency virus (HIV) infection on the off chance that she is presented to HIV and expanded danger for mortality. Vaginal infection among pregnant women may cause complication for both mother and baby: for mother can cause premature rupture of the membranes, preterm delivery, postpartum endometritis and post abortion infections. For baby: low birth weight, fetal wastage, chorioamnionitis, baby visual deficiency, neonatal pneumonia, and mental retardation [9].

Numerous women are self-analyzed and self-treated from vaginal infection scenes with over -the- counter (OTC) medications that may accordingly give a background marked by recurrence and never affirmed her disease by microbiological tests [10]. American social health association (ASHA) (2013)[11] reported that, 70\% of women self-treated vaginal infections before calling a medicinal services supplier. Frequently they inaccurately thought they had a yeast infection when, truth be told, it was bacterial vaginosis (BV). Along these lines, it is essential to affirm the finding by microbiological tests and full sexual wellbeing screen to exclude concurrent infection $[11,12]$.

Managing vaginal infections rested on the nurse to modify the practices and to improve and prevent recurrence of vaginal infections. The prevention requires changing in self-care practices that put the women under the risk of infection, and the women should be taught about the most common symptoms and risk factors for vaginal infections [13, 14].

Self- care practices refer to activities and attitudes, which add to the upkeep of prosperity and personal wellbeing and advance human improvement. As far as health maintenance, self-care is any action as a person with the expectation of enhancing or reestablishing wellbeing, or treating or anticipating sickness. Vaginal infection related self-care themes include: personal hygiene, vaginal hygiene, sexual hygiene, menstrual hygiene, and toilet hygienic practices. Self- care is seen as a halfway answer for the worldwide ascent in medicinal services costs put on governments. The notion that self-care is a major 
mainstay of health, and social consideration implies it is a vital part of a modern human services framework administered by bureaucracy and legislation $[\mathbf{1 4}, \mathbf{1 5}]$.

Concern has been raised by world health organization (WHO) (2015)[16] about whether vaginal, sexual or menstrual self-practices could have harmful effects such as; increasing the susceptibility to sexually transmitted infection (STI) or reproductive tract infection (RTI). They recommend that more evidence is needed to confirm a correlation between an increased risk of STI and HIV/ acquired immune deficiency syndrome (AIDS) and vaginal practices, but they are modifiable through health education and prevention messages by the maternity nurses. Therefore, this study was carried out to investigate the aforementioned parameters of self-practices and demonstrate the nursing role in its solution.

\section{Aim of the study}

This study was aimed to evaluate the impact of educational program on the improvement of self- care practices among women diagnosed with vaginitis in Ismailia City.

\section{Research Design:}

\section{Subjects and Methods}

Aquasi-experimental study design was adopted in this study.

\section{Study settings:}

This study was carried out at three gynecological \& family planning clinics in primary health care (PHC) centers which cover all available sectors in Ismailia city.

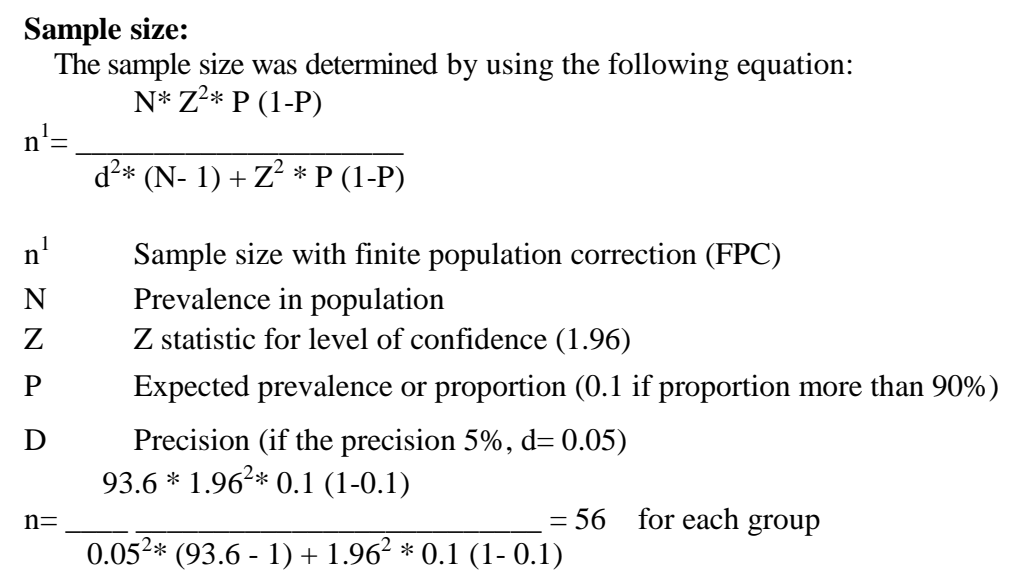

The study population consisted of 124 women determined by the previous equation and after addition of $10 \%$ to compensate for dropout.

Study sampling:

Convenient sample was used to recruit the needed sample. The numbers of women recruited were 124 as 40 women from each center approximately. The first 64 women assigned as comparison group and the followed 60 was assigned as study group. Study group: those women who attended the training program about the self-care practices of genital tract hygiene. Control Group: those women who received the maternal, child health $(\mathrm{MCH})$ routine care of the health sitting (medications prescribed by physician).

Sample criteria: any woman attending the above-mentioned study setting during the time of the study was eligible for inclusion in the study sample if she fulfills the following eligibility criteria: Recently medically diagnosed with vaginal infection; age ranging between 18-35 years; and married women. The study sample designed from,

\section{Tools of data collection:}

1-Interviewing questionnaire form: This tool describes the woman profile which consists of four parts: The first part includes: woman's socio-demographic such as age, level of education, job status, income, husband education and job, as well as the identification data as the address and telephone number for follow-up. The second part includes the history: obstetrical, gynecological, and family planning history, including medication intake. The third part: include questions regarding current signs and symptoms of vaginal infection, the complains of their husbands and the management prescribed for this condition. The forth part: data about methods of diagnosis and medication described. hygiene.

2-Evaluation form: include: women self-care practices related to the general, genital, menstrual and sexual

\section{Scoring system of self-care practices:}

For the practice items, the applied practice was scored 2, the sometimes applied 1 and not applied scored 0 . The scores of the items were summed-up and the total divided by the number of the items, giving a mean score for the part. These scores were converted into a percent score, and means and standard deviations were computed. Practice was considered satisfactory if the percent score was $60 \%$ or more and unsatisfactory less than $60 \%$ 
3-Follow up record: which designed mainly to evaluate the response of women have vaginal infection to the selfcare practices program. It also indicates the action taken for those who had negative response to such modality of management. The follow up took a period of 3 months after the program.

\section{Content validity:}

The tool was revised by five juries for clarity, relevance, applicability, comprehensiveness, understanding and ease for implementation. According to their suggestions, the modifications were applied.

\section{Pilot Study:}

Ten percent (12 women) of the total sample was used as a pilot study. The purpose of the pilot study was to test the applicability, to clarify the feasibility and clarity of the tools and to test the sequence of questions to maintain consistency. Also, served to estimate the time needed to complete the tool, helped to find out any problems that might interfere with data collection, and to determine the appropriate data and time for data collection. According to the results of the pilot study, the necessary modifications in the tool were carried out. The women in the pilot study were not enrolled in the study.

\section{Fieldwork:}

\section{Assessment phase:}

A general survey was first performed by using past research efforts to evaluate the self-care practices that are associated with vaginal infections among high risk women in Ismailia city.

\section{Planning phase:}

An educational program was designed about self- care practices regarding vaginal infections. The educational program aimed to improving the women's knowledge and practice related to genital self-care practices was designed by the researchers based on a scientific background, and on the light of the needs identified during the pre-test assessment. The program included educating and training of women about the importance and components of genital tract hygiene as well as detailed instruction about the treatment prescribed. It involved both theoretical and practical training. Theoretical background included vaginal infection sources, risk factors...etc and practical training included vaginal medication administration and hand washing.

\section{Implementation phase:}

Data were collected from July to October 2015. Data collected daily during implementation phase and every two days per week for follow up, each PHC center visited from 8:00 AM to 1:30 PM. The researcher interviewed the women and filled the interviewing tool from each woman individually. The approximate time spent with each woman during the interviewing was 10 minutes in pre and post-test assessment.

The program was administered to members of the study group only. This was done in small groups (4:6 women / session). Different and suitable teaching methods were used including booklet, posters \& leaflets; computer data show presentation, real experiences \& role playing and demonstration with model. Evaluation of women's knowledge and practices regarding self-care of their genital hygiene was done after the program using the same tools.

\section{Evaluation phase:}

Evaluation of women's knowledge and practices regarding self-care of their genital hygiene was done after the program using the same tools. This was done for both study and control groups. Additionally, the outcomes of the program were compared between the study and control groups.

\section{Administrative Design \& Ethical Consideration}

An official approval letters directed from the Dean of the Faculty of Nursing at Suez Canal University to the medical and nursing directors of heath centers, aiming to ensure their cooperation and permission to fulfill the work after explaining for them the purpose and objectives of the study. The aim of the study has been explained to directors at PHC centers to gain cooperation before asking women to participate in the study, stressing on confidentiality of the collected information, also written consent was gained. The researcher emphasized that participation were absolutely voluntary and professional nursing help was provided whenever needed.

\section{Statistical analysis}

Data entry and analysis were done using SPSS 23.0 (statistical packages for social science). Qualitative variables were compared using chi-square test. Whenever the expected value in the cells in $2 \times 2$ tables was less than 5, Fisher test was used instead. In larger than 2x2 tables, Monti carlo test could be applied whenever the expected value in $10 \%$ or more of the cells was less than 5. Statistical significance was considered at $p$-value $<0.05$.

\section{Results}

1. The most satisfactory self-care practices were those related to menstrual hygiene (34.7\%) followed by sexual hygienic practices $(27.4 \%)$. The least satisfactory self-care practices were those related to perineal hygiene (3.2\%).

2. Almost three quarters $(73.3 \%)$ of the study group had satisfactory compliance to the prescribed treatment compared to $46.9 \%$ of the control group. Meanwhile, they were significantly more likely to use the prescribed vaginal treatment and avoid sexual intercourse during the treatment $(70.5 \%$ \& $73.3 \%$ vs. $13.1 \%$ \& $15.6 \%$ respectively). Differences observed are statistically significant $(\mathrm{P}<0.01)$.

3. Women self-care practices related general, perineal, menstrual and sexual hygiene throughout program phases is demonstrated that the mean score of self-care practices were partially the same among both the study and control groups 
before the intervention. However, statistically significant improvements were revealed in all areas at both the post $(\mathrm{p}<0.001)$ and follow-up phases $(\mathrm{p}<0.001)$. The mean score was greatly increased among the study group "at the first follow up" in all the parameters of self-care practices, specifically perineal and menstrual hygiene $(11.06 \pm 1.24 \&$ $5.24 \pm 1.13$ vs. $6.64 \pm 2.08 \& 1.4 \pm .86$ respectively). However, the mean score of adequate practice declined at the second follow-up phase in all areas. Nonetheless, the mean score of adequate practice remained higher among women in the study group than women in the control group in all areas.

4. The end result of women response to the protocol of management indicated that by the first follow up women in the study group were significantly more likely to reach complete improvement compared to the control group (68.3\% vs. $10.4 \%$ ). Meanwhile, surprising enough as much as $87.8 \%$ of the control group did face recurrence of symptoms at the second follow up after 3 months.

\section{VII.Discussion}

The current study assessed the practice of women in the study and control groups about vaginal infection and hygienic self-care practices before the intervention. The findings indicated discrepancies between the two groups, with women in the study group having better knowledge in some areas and women in the control group in other areas. Nevertheless, they both had similarly low satisfactory total practice of the problem and all related self-care hygienic practices with about one third of them having satisfactory practices about menstrual hygienic practices followed by sexual hygienic practices. The least satisfactory self-care practices were those related to perineal hygiene. This unsatisfactory level of practices reflects deficiency in woman knowledge as well as some deficiency in the role of the maternity nurses in the area of vaginal infection and its relation to self-care hygienic practices. Thus, although women may be convinced with the importance of this issue, they may not receive adequate information and counseling regarding methods to prevent infection and to follow treatment instruction while seeking this service. In agreement with this, $[\mathbf{9 , 1 4 ]}$ emphasized that greater efforts to improve the quality and uptake of educational interventions implemented through gynecological setting are necessary to increase their effectiveness.

The common barrier to the treatment for patients with vaginal infection may be related to their lack of awareness about such problem, its causes, consequences, and available treatment. In this regard Sevil, et al,. (2013)[17] found that patients often did not perceive vaginal infection as an abnormal or a serious medical condition. Hamed, (2015)[18] and [14] further supported this idea that women were less likely to consider their symptoms a disease state and often were completely unaware of available intervention. Furthermore, Bilardi, (2013)[19] reported that most of patients with vaginal infection do not seek help due to embarrassment and unawareness that help is available.

Women frequently did not discuss their symptoms with their physician due to embarrassment or misconception that vaginal infection is not a medical condition and they could manage on their own. They experience the feeling of shyness and stigma to report symptoms or to discuss this problem with any one. Thulkar, et al., (2010)[9] added that patients do not seek help because under-recognition of health care providers that vaginitis is a significant clinical problem. Lack of maternity nurse's orientation regarding the importance of counseling and assisting woman to compile to the management protocol as well as persistent major gaps in their understanding of the natural history, risk factors, related misconception and the most effective treatment constitute the main goal that the researcher took into consideration while implementing the program.

The implementation of the current study intervention led to significant improvements of the women practices in the study group compared with the control group. The findings are certainly related to the content of the educational program, which was custom-tailored to the needs of the patients, and its process, which followed the principles of adult learning with more active participation and open discussions and using simulations in order to simplify the information and help attendants to apply their knowledge to practice.

Women within the study group were significantly more likely to reach complete improvement compared to the control group during the first follow up. Women who followed self-care practices had higher cure percent compared to those who did not receive it, which indicates that self-care practices modifications are useful in improving and preventing recurrent of vaginal infections. This finding is in line with that of Sevil, et al., (2013) [17], who found in their study that improvement among the control group was delayed than that of the study group during post assessment. This is attributed to the effect of routine health center management they received.

Concerning the recurrence of infection, the control group was significantly more likely to complain of recurrent infection compared with the study group. In this, respect Thulkar, et al. (2010)[9] reported that the underlying cause of recurrence appears after pregnancy, with the use of IUD, or noncompliance to the treatment. Hainer \& Gibson, (2011)[20] found evidence that women compiled to the treatment protocol and follow instruction given about self-care hygienic practices were exposed to less recurrence of infection. Thus, an important part to the effort to prevent women from vaginal infections is the integration of behavior change and medical treatment. It is suggested that women diagnosed with vaginal infections should not only receive medical treatment but also be educated about the impact of behavioral risk factors on their diseases. Similar successful educational interventions were also reported [21]. These successes of educational programs may be attributed to the accessibility of information from program and its attached booklet and the changes in women perception about the importance of compiling to the management protocol [21, 22].

\section{Conclusion}

Based on the findings of the present study results, it can be concluded that, the women receiving self-care practices program showed an improvement of their self-care practices and positively respond to the protocol of management of combating vaginal infection and had less recurrence than those who did not receive the program. 


\section{Recommendation}

The current study recommended that, the importance of planning and implementing necessary educational program about genital hygienic practices to create awareness and prioritize problems. A brochure about vaginal infection and hygienic self-care practices should be disseminated to vulnerable women and their husbands. Infected women educated to recognize the adverse effect of recurrent infection, the importance of early screening, using the prescribed medication and avoiding practices found to be harmful. Further research concerning the effects of unhygienic practices should be performed to provide appropriate information and lead to standard recommendations in women's health care.

Figure (1): Self-care practices about genital hygiene among the studied women before the intervention $(\mathrm{n}=124)$ :

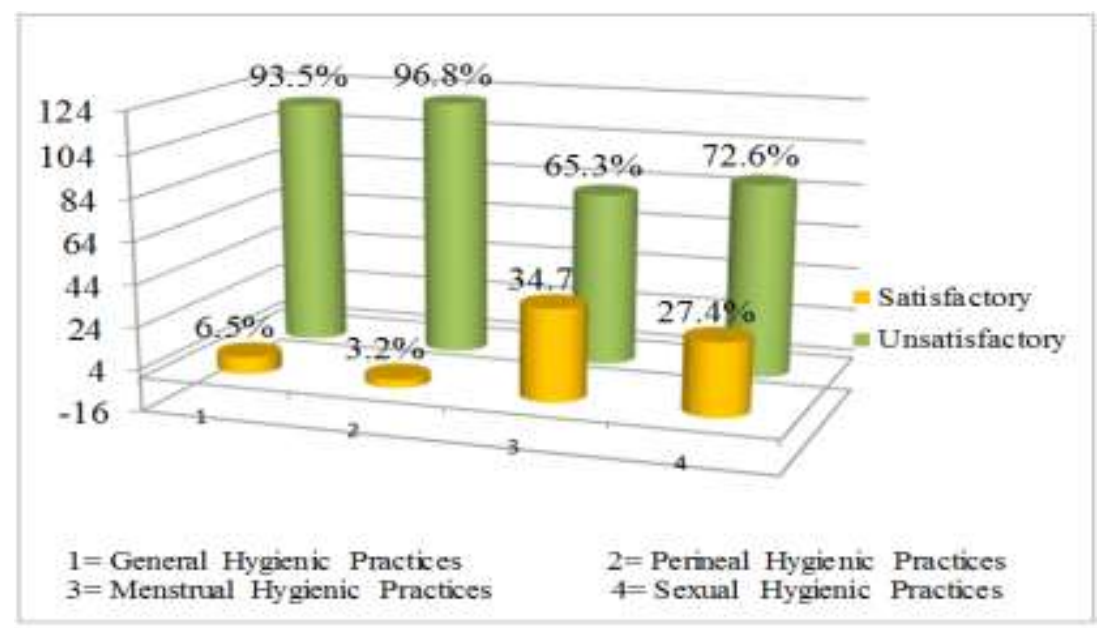

Table (1) Distribution of studied women according to their compliance to the regimen of treatment prescribed

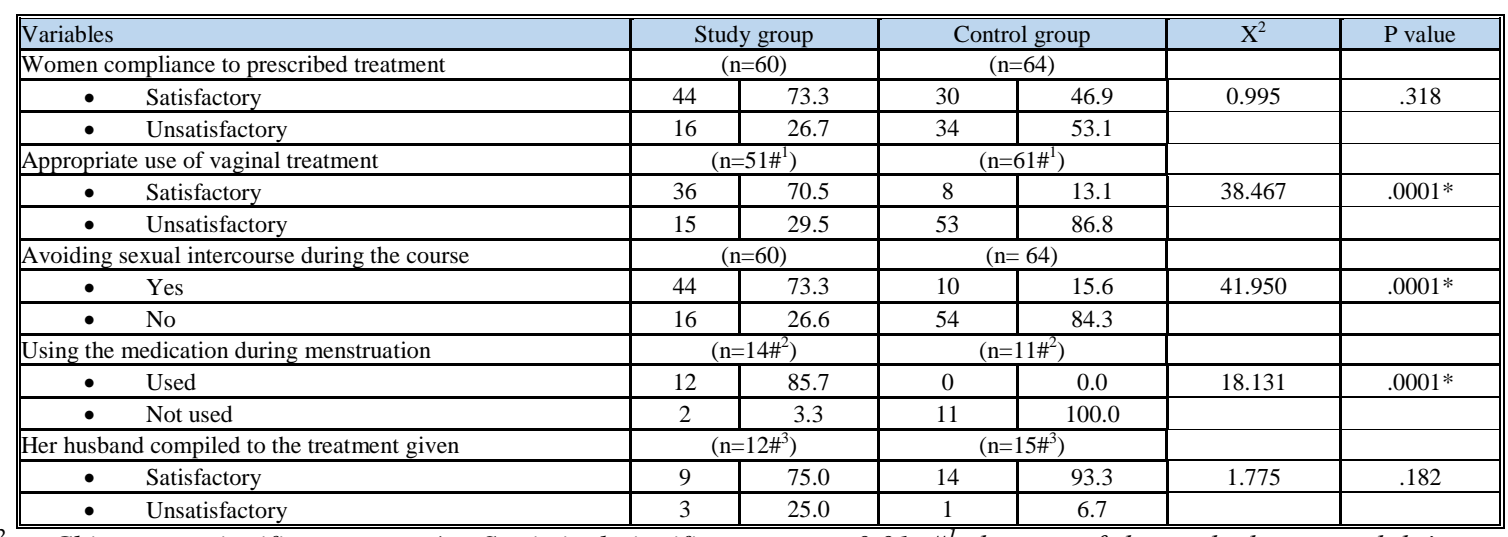

$X^{2}=$ Chi square significance test, ${ }^{*}=$ Statistical significance at $p<0.01, \#^{1}$ the rest of the studied women didn't receive vaginal treatment, $\#^{2}$ the rest of the studied women didn't had menstruation, $\#^{3}$ the rest of the husbands didn't receive treatment.

Table (2): The studied women's responses to self-care practices throughout the study phases $(\mathrm{n}=124)$ :

\begin{tabular}{|c|c|c|c|c|c|c|c|c|}
\hline \multirow{3}{*}{ Variables } & \multirow{2}{*}{\multicolumn{3}{|c|}{$\begin{array}{c}\begin{array}{c}\text { Study group } \\
(\mathrm{n}=60)\end{array} \\
\text { Mean } \pm \text { SD } \\
\end{array}$}} & \multirow{2}{*}{\multicolumn{3}{|c|}{$\begin{array}{c}\begin{array}{c}\text { Control group } \\
(n=64)\end{array} \\
\text { Mean } \pm \text { SD } \\
\end{array}$}} & \multirow{3}{*}{$\begin{array}{c}\text { T test } \\
\text { (3 months) }\end{array}$} & \multirow{3}{*}{ P value } \\
\hline & & & & & & & & \\
\hline & $\begin{array}{l}\text { Before the } \\
\text { intervention }\end{array}$ & \begin{tabular}{|c|}
$\begin{array}{c}1^{\text {st }} \text { follow up } \\
\text { (after } 7 \text { to } 10 \\
\text { days) }\end{array}$ \\
\end{tabular} & \begin{tabular}{|c|}
$2^{\text {nd }}$ follow \\
up (After 3 \\
months) \\
\end{tabular} & $\begin{array}{c}\text { Before the } \\
\text { intervention }\end{array}$ & \begin{tabular}{|c|}
$\begin{array}{c}1^{\text {st }} \text { follow up } \\
\text { (after } 7 \text { to } 10 \\
\text { days })\end{array}$ \\
\end{tabular} & \begin{tabular}{|c|}
$2^{\text {nd }}$ follow \\
up (After 3 \\
months) \\
\end{tabular} & & \\
\hline $\begin{array}{l}\text { General Hygienic Practices } \\
\text { (score }=13)\end{array}$ & $4.20 \pm 1.65$ & $9.87 \pm 1.98$ & $7.89 \pm 2.15$ & $4.15 \pm 1.64$ & $4.15 \pm 1.64$ & $4.15 \pm 1.64$ & 10.932 & $.0001^{*}$ \\
\hline $\begin{array}{l}\begin{array}{l}\text { Perineal Hygienic Practices } \\
\text { (score=14) }\end{array} \\
\end{array}$ & $6.60 \pm 2.07$ & $11.06 \pm 1.24$ & $10.85 \pm 1.56$ & $6.64 \pm 2.08$ & $6.64 \pm 2.08$ & $6.64 \pm 2.08$ & 13.011 & 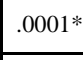 \\
\hline $\begin{array}{l}\text { Menstrual Hygienic Practices } \\
\text { (score=7) }\end{array}$ & 95 & .13 & .55 & $1.4 \pm .86$ & $.40 \pm .86$ & $4 \pm .86$ & 15.676 & $.0001^{*}$ \\
\hline Sexual Hygienic Practices $($ score $=9$ ) & $3.55 \pm 1.54$ & $6.75 \pm 1.66$ & $5.4 \pm 1.87$ & $3.78 \pm 1.70$ & $3.78 \pm 1.70$ & $3.78 \pm 1.70$ & 5.037 & $.0001^{*}$ \\
\hline
\end{tabular}

T test $=$ independent $t$ test, $*=$ Statistical significance at $p<0.01$

NB: At the second follow up "after 3 month" drop out occur for $23.34 \%(n=14)$ women in the control group and $23.45 \%$ $(n=15)$ in the study group 
Table (3): Distribution of the studied women according to the end result of the intervention:

\begin{tabular}{|c|c|c|c|c|c|c|c|}
\hline \multirow{2}{*}{\multicolumn{2}{|c|}{ Variables }} & \multicolumn{2}{|c|}{$\begin{array}{c}\text { Study group } \\
(\mathrm{n}=60)\end{array}$} & \multicolumn{2}{|c|}{$\begin{array}{c}\text { Control group } \\
(\mathrm{n}=64)\end{array}$} & \multirow[t]{2}{*}{$\mathrm{X}^{2}$} & \multirow[t]{2}{*}{$P$ value } \\
\hline & & No. & $\%$ & No. & $\%$ & & \\
\hline \multicolumn{8}{|c|}{ Improvement in $1^{\text {st }}$ follow up } \\
\hline$\bullet$ & Complete improvement & 41 & 68.3 & 10 & 6.4 & 73.780 & $.0001^{*}$ \\
\hline$\bullet$ & Still have some discharge. & 16 & 26.7 & 15 & 9.6 & & \\
\hline$\bullet$ & Not Improved & 3 & 5.0 & 39 & 39.1 & & \\
\hline \multicolumn{8}{|c|}{ Recurrence of infection in $2^{\text {nd }}$ follow-up after 3 months \# } \\
\hline$\bullet$ & Recurrent & 10 & 21.8 & 43 & 87.8 & 67.434 & $.0001^{*}$ \\
\hline$\bullet$ & Not recurrent & 36 & 78.2 & 6 & 12.2 & & \\
\hline
\end{tabular}

$X^{2}=$ Chi square significance test, ${ }^{*}=$ Statistical significance at $p<0.01, \#(76.66 \%(n=46))$ of study and $(76.56 \%(n=49))$ of control, the researcher unable to contact the rest of women for the $3^{\text {rd }}$ month follow-up.

\section{References}

[1] N. R Johnson, Vaginitis and Vulvitis. In E.A. Reece (Ed.) Obstetrics and Gynecology: The Essentials of Clinical Care. $4^{\text {th }}$ Ed.; 1 (30) (Saunders: Elsevier 2010) 293-4.

[2] S. Ejder Apay, F. Özdemir, E. Nazik, D. Coşkuner Potur, A. Hadimli, D. Tanriverdi, S. Aktaş, E. Y Özorhan, T.Sakar, Y. Doğan Merih, C. Alaca, \& A.Yurttaş, Yedi Farkli Ildeki Kadinlarin Genital Hijyen Davranişlarinin Belirlenmesi: Çok Merkezli Kesitsel Bir Çaliş̧ma, Journal of Anatolia Nursing and Health Sciences; 2014, 17

[3] A. Ünsal, Universite Okuyan Kız Öğrencilerin Genital Hijyen Davranıș ları, Firat Sağllk Hizmetleri Dergisi; 5, $2010 ;$;9-93.

[4] S. ÖZDEMIR, T. ORTABAĐ, B. TOSUN, Ö. ÖZDEMIR, \& H. BEBIP, Assessment of the knowledge level and behaviors of students in school of nursing about genital hygiene. Gulhane Med J, 54, 2012; 120-128.

[5] J.E. Allsworth,. \& J.F. PEIPERT, Prevalence of bacterial vaginosis, National Health and Nutrition Examination Survey data 2001-2004. Obstetrics and gynecology 2007; 109:114-120.

[6] National Health Service (NHS) Choices, Causes of vaginal thrush. Available at http://www.nhs.uk/Conditions/Thrush/Pages/Introduction.aspx, page last reviewed: 04/03/2016

[7] J.D. Sobel, Vulvovaginal candidosis. Lancet (London, England 2007) 369:1961 - 71

[8] P. Gupte, S. Patil \& R. Pawaskar, Vulvovaginal hygiene and care. Indian Journal of Sexually Transmitted Diseases and AIDS, 30,$2009 ; 130-33$.

[9] J. Thulkar, A. Kriplani, N. Agarwal \& S. Vishnubhatla, Aetiology\& risk factors of recurrent vaginitis \& its association with various contraceptive methods. Indian J Med Res, 131, 2010; 83-7.

[10] J.S. Berek, R.D. Rinehart \& T.C. Hengest (Lippincott Williams \& Wilkins 2007) Genitourinary infection and Sexually transmitted diseases. Berek \& Novak's Gynecology $4^{\text {th }}$ Ed.; 16: 542- 47.

[11] American Social Health Association (ASHA) Vaginitis (Menlo Research Triangle Park, 2013). Available from asha, creating asexual health nation at: www.ashasexualhealth.org.

[12] R. H. Schnatz \& A.M. Miranda, Vaginal Anatomy. Available at www.emedicine.medscape.com, 2011

[13] S. Ricci \& T. Kyle, Maternity and pediatric nursing, $4^{\text {th }}$ Ed. 5 (Wolters kluwer health, Lippincott Williams \& Wilkins 2009$) 143,151$.

[14] Z.A.A. BARAIA, N.S. SHALABY \& H. M. IMAM, Health Behaviors for Vaginal Infection among Married Women in Ismailia City, master diss, Suez Canal University, 2014

[15] Kollack \& Ingrid, The Concept of Self Care, in Kim, Hesook Suzie; Kollak, Ingrid. Nursing Theories: Conceptual and Philosophical Foundations, 45 (Springer Publishing Company 2006) ISBN 0826140068. Retrieved 31 August 2013.

[16] World Health Organization, A multi-country study on gender, sexuality and vaginal practices: Implications for sexual health. Department of Reproductive Health and Research 2015.

[17] S. Sevil, O. Kevser, U. Aleattin, A. Dilek, \& N. Tijen, An Evaluation of the Relationship between Genital Hygiene Practices, Genital Infection. Gynecology \& Obstetrics, 3, 2013.

[18] A. G. Hamed, The Impact of Genital Hygiene Practices on the Occurrence of Vaginal Infection and the Development of a Nursing Fact Sheet as Prevention Massage for Vulnrable Women. IOSR Journal of Nursing a nd Health Science (IOSR-JNHS) 4, 2015, 55-64.

[19] J. E. Bilardi, S. Walker, M. Temple-Smith, R. Mcnair, J. Mooney-Somers, C. Bellhouse, C.K. Fairley, M.Y. Chen, \& C. Bradshaw, The Burden of Bacterial Vaginosis: Women's Experience of the Physical, Emotional, Sexual and Social Impact of Living with Recurrent Bacterial Vaginosis. 2013; 8(9): e74378.

[20] B. L. HAINER \& M. V. GIBSON, Vaginitis: Diagnosis and Treatment. Am Fam Physician, 2011 Apr 1;83(7):807-815.

[21] Calgary, Sexual \& Reproductive Health, Excerpt from - Alberta Health Services Calgary Zone. (2013). TEENS AND TRENDS: Get the Facts on Teen Sexuality.

[22] S.O. Aral, M. Over, L. Manhart \& K. K. Holmes, Sexually Transmitted Infections from D.T. Jamison, J.G. Breman, A.R. Measham, et al., editors Disease Control Priorities in Developing Countries. $2^{\text {nd }}$ Ed. Washington (DC): The International Bank for Reconstruction and Development / The World Bank; 2006. Co-published by Oxford University Press, New York;(17) 